\title{
Le musée de la Nacre et de la Tabletterie, un conservatoire du savoir-faire
}

\section{Catherine Cardinal}

\section{(2) OpenEdition}

1 Journals

\section{Édition électronique}

URL : http://journals.openedition.org/artefact/516

DOI : $10.4000 /$ artefact.516

ISSN : 2606-9245

Éditeur:

Association Artefact. Techniques histoire et sciences humaines, Presses universitaires du Midi

\section{Édition imprimée}

Date de publication : 1 octobre 2016

Pagination : 315-317

ISBN : 978-2-7535-5174-9

ISSN : 2273-0753

\section{Référence électronique}

Catherine Cardinal, « Le musée de la Nacre et de la Tabletterie, un conservatoire du savoir-faire », Artefact [En ligne], 4 | 2016, mis en ligne le 07 juillet 2017, consulté le 15 septembre 2020. URL : http:// journals.openedition.org/artefact/516

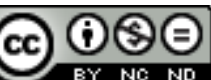

Artefact, Techniques, histoire et sciences humaines est mise à disposition selon les termes de la Licence Creative Commons Attribution - Pas d'Utilisation Commerciale - Pas de Modification 4.0 International. 


\section{Le musée de la Nacre et de la Tabletterie, un conservatoire du savoir-faire}

Catherine CARDINAL

La ville de Méru (Oise) trouve une expression de son passé technique et de son originalité économique dans un musée consacré à l'histoire de la tabletterie. Cette activité, débutée dans la seconde moitié du $\mathrm{XvI}^{\mathrm{e}}$ siècle, se développe considérablement jusque dans les années 1920. Le musée la met en lumière non seulement à travers la présentation de collections permanentes et d'expositions, mais aussi par des démonstrations faites sur des machines provenant des anciens ateliers ${ }^{1}$.

Comme la plupart des " écomusées ", l'idée du musée est née dans le milieu des fabricants qui ont souhaité, dès les années 1960, garder des traces d'une production qui réunit plus de 10000 personnes vers 1910. Le projet s'affermit alors que la fermeture de la dernière usine, en 1972, accentuait la nécessité de prendre des mesures de sauvegarde. L'Écomusée des pays de l'Oise, créé à Beauvais en 1978, apporta son soutien en réunissant les premières archives orales et photographiques, tandis que diverses associations, comme celle des Amis du Musée, formée en 1986, récupéraient du matériel. Dans la dernière décennie du $\mathrm{xx}^{\mathrm{e}}$ siècle, avec des financements des col- lectivités locales, le musée est créé dans une usine datant de 1857 pour ses parties les plus anciennes. Caractéristique des industries du Nord, avec ses murs en brique et ses verrières, elle est inscrite à l'Inventaire supplémentaire des monuments historiques depuis 1994 (illustration 16 , cahier couleur).

Ouvert en 1999, le musée ${ }^{2}$ occupe le bâtiment central qui accueillait une centaine d'ouvriers et qui, aujourd'hui, restitue une évocation de leur travail, nonobstant le bruit assourdissant et la poussière étouffante auxquels ils étaient soumis dix heures par jour. Une machine à vapeur (illustration 17, cahier couleur) fonctionne pour permettre l'activité de l'atelier des boutonniers qui ouvre, au rez-de-chaussée, le parcours muséographique. Reconstitué comme à l'origine, il témoigne de la principale production de Méru entre les années 1880 et 1920, la boutonnerie de nacre, qui lui valut d'être désignée comme la « capitale mondiale de la nacre ${ }^{3}$ » (illustration 18, cahier couleur).

La réussite du musée est d'immerger le public dans la fabrication des boutons, en lui montrant ses phases successives (la taille, le meulage, le perçage, le 
polissage, la gravure, la teinture) et en le conduisant finalement devant le bureau du contremaître qui pesait et payait le travail de la journée avant d'expédier les lots dans le bourg où l'encartage des boutons était fait par les femmes (illustration 19, cahier couleur). La division du travail, la précision des gestes coordonnés de poste en poste, les procédés de mécanisation sont rendus visibles, ainsi que le souhaitaient les concepteurs.

Une autre spécialité a fait la gloire de la localité, celle des dominos. Le musée l'évoque dans un autre atelier où un dominotier offre de suivre les opérations de leur fabrication, de la préparation de l'os de bœuf ou de l'ébène jusqu'au perçage et au mouchetage.

Entraînés au premier étage, les visiteurs découvrent le raffinement des objets fabriqués par les tabletiers dans des matières naturelles dures, nacre, os, bois, corne, écaille, ivoire. Sont exposés des éventails, des pommeaux de cannes, des jumelles de théâtre, des carnets de bal, des jeux d'échecs et de dominos, des couverts de table, des brosses de toilette. Des documents d'archives, des bornes multimédias, des machines et outils accompagnent la présentation des pièces.

Labellisé "musée de France ", le musée de la Nacre et de la Tabletterie bénéficie depuis 2010 de salles aménagées dans une aile de l'usine, raccordée par une passerelle, afin de compléter ses offres d'expositions, d'activité pédagogiques et de conférences.

\section{L'exposition L'éventail. Matières d'excellence}

Le musée proposaitjusqu'en août 2016, une exposition consacrée à une troisième spécialité de Méru et de ses environs, depuis le $\mathrm{XVIII}^{\mathrm{e}}$ siècle : la fabrication des montures d'éventails principalement en nacre, en corne et en bois.

Les commissaires, Georgina LetourmyBordier, historienne de l'art, et Sylvain Le Guen, éventailliste, ont privilégié comme thématique « l'usage des matières et leur variété » et tenté de mettre en lumière les innovations techniques qui marquent l'histoire de cet accessoire de luxe. S'appuyant sur de nouvelles recherches dans les archives et leur connaissance des objets, ils ont réalisé une exposition séduisante par l'élégance et la préciosité des pièces et contribuant à une meilleure connaissance des procédés de fabrication. Les vitrines furent aménagées pour montrer la mise en œuvre des différentes matières utilisées (bois, os, corne, ivoire, écaille, nacre) et permettre l'observation des techniques de décoration des brins et des panaches, telles le découpage, le reperçage, la gravure, la ciselure, l'incrustation, la dorure, la teinture (illustration 20, cahier couleur). Comme les éventails choisis le prouvent, les innovations sont nombreuses au $\mathrm{XIX}^{\mathrm{e}}$ siècle : utilisation de matières nouvelles, mise au point $d^{\prime}$ " éventails à nécessaires ", d'éventails à ouverture automatique. D'exceptionnelles pièces signées témoignent des inventions techniques de plusieurs tabletiers de l'Oise 
récompensés dans les expositions internationales. Citons Louis-Isidore Bastard (1829-1884), propriétaire d'un brevet pour « une sculpture par application dans la fabrication des panaches d'éventails ", Jules Vaillant (1836-1900), sculpteur sur ivoire, Georges Bastard (1881-1939), le " rénovateur de l'éventail », spécialiste du travail de la nacre et de la corne. Une centaine d'œuvres, sorties de collections privées, firent apprécier la créativité artistique des éventaillistes, inséparable de la dextérité technique qui la rend possible.

La pertinence de l'exposition et son attrait ont permis à ses commissaires d'obtenir suffisamment de prêts pour renouveler trois fois le choix des pièces entre septembre 2015 et août 2016 (illustration 21, cahier couleur). Gageons qu'une telle manifestation favorisera le développement du musée en attirant les donateurs et les visiteurs. Dans l'avancement de la recherche sur l'histoire de l'éventail, elle marque une étape en se focalisant sur la fabrication de sa monture et non sur la décoration de ses feuilles qui retient généralement l'attention des chercheurs. Le catalogue restera un ouvrage de référence, offrant des études inédites en plus d'une abondante illustration ${ }^{4}$.

\section{Notes}

1. Mes remerciements s'adressent à Véronique Portier, responsable du musée, Céline Louvet, Georgina Letourmy-Bordier, Sylvain Le Guen pour leur aimable accueil et leurs précieuses informations.

2. 51 Rue Roger Salengro, 60110 Méru, site [http://musee-nacre.com/].

3. Sur la tabletterie à Méru, Laurence BonNET, La nacre. La tabletterie, le bouton, l'éventail, Méru, Édition District des Sablons, 1998. Plus généralement, sur les boutons, on rappellera la très riche exposition Déboutonner la mode, présentée au musée des Arts décoratifs (Paris), 10 février-19 juillet 2015 (commissaire : Véronique Belloir, historienne de la mode, chargée des collections $x^{\mathrm{e}}$ siècle au Palais Galliera), présentation en ligne sur [http://www. lesartsdecoratifs.fr/francais / musees / musee-desarts-decoratifs / actualites/expositions-terminees / mode-et-textile/deboutonner-la-mode].

4. Georgina Letourmy-Bordier, Sylvain Le Guen, L'éventail. Matières d'excellence : la nature sublimée par les mains de l'artisan [catalogue d'exposition], Villeneuve-les-Sablons, Communauté de communes des Sablons, 2015. 